\title{
Investigating the Relationship between Learning Styles and ESP Reading Strategies in Academic Setting
}

Parviz Ajideh, Mohammad Zohrabi, Kazem Pouralvar*

Faculty of Foreign Languages and Persian Literature, English Department, University of Tabriz, Tabriz, Iran

Corresponding Author: Kazem Pouralvar, E-mail: k.pouralvar@gmail.com

\section{ARTICLE INFO}

Article history

Received: December 24, 2017

Accepted: February 04, 2018

Published: May 01, 2018

Volume: 7 Issue: 3

Advance access: March 2018

Conflicts of interest: None

Funding: None

\begin{abstract}
The present study investigated the relationship between Art and Science students' learning styles and their ESP reading strategies in academic settings. Learning styles are defined as general orientations learners take toward their learning experiences. This notion has recently obtained attention in the area of language learning. Strategies are also defined as specific behaviours or techniques learners employ towards leaning in order to achieve their learning goals. The strategies chosen are often linked to the individual's learning style. The purpose of this study was to identify Art and Science students' major learning style preferences and their strategies they employ to tackle their reading materials in ESP courses at Tabriz Islamic Art University. To this end, 313 Art and Science students at Tabriz Islamic Art University answered two selfreport questionnaires (PLSPQ and SORS) to identify their major and minor learning styles as well as their reading strategies in ESP reading. In order to find any relationship between the students' preferred learning style (s) and their reading strategies in ESP, Pearson Product Moment Coefficient $r$ was used to analyze the participants' answers to the questionnaires. The results showed that Art students favored Kinesthetic, Auditory, Visual and Tactile learning styles as their major learning styles while Science students showed preference to only Kinesthetic Learning style as their major learning style and other learning styles as their minor ones. It was also found that the most dominant reading strategies both Art and Science students apply in reading their ESP texts was cognitive strategies. Correlational analyses of their major learning styles and their reading strategies are discussed.
\end{abstract}

Key words: Learning Styles, Reading Strategies, ESP, PLSPQ, SORS

\section{INTRODUCTION}

The notion of learning styles and strategies has recently attracted wide attention in the realm of education in general and TEFL in particular. It is repeatedly claimed that learners bring their individual learning styles and strategies into their learning experiences. In fact, it is proved that learning styles and strategies, as individualistic traits, pave the way for learners to embark on their cognitive abilities and rev up their learning experiences. Psychological research has shown that there are quite different ways of viewing the world and approaching learning. For instance, some people are divergent thinkers; others are convergent thinkers. Our general approach may be predominantly right-brained (glob$\mathrm{al} /$ holistic) or left-brained (analytical) or a mixture of both. Analytic, left-brained thinkers are highly verbal, linear, logical and temporal whilst global, right-brained thinkers are highly visual and spatial, intuitive and relational (parts to whole) (Kinsella, 1995).

Our culture also affects our learning styles. Learning is a social process and so attitudes to learning and views of language have a cultural dimension to them, determined by national culture, professional culture and individual culture. For example, it is suggested that Asian students look for structured learning, with a teacher as an authority figure and are less comfortable with autonomous learning and situations where there are several acceptable answers. Hispanics are more likely to develop a global learning style and accept flexibility and negotiation while Anglo-Americans are more analytical wanting planned, methodical approaches (Kinsella, 1995).

In language learning significant factors are also the extent to which an individual is visually, aurally or kinaesthetically oriented. Visually oriented learners need to see words to remember them and will read and write a lot; auditory oriented learners can recall pronunciation and meaning from hearing only. Kinaesthetic learners are stimulated by touch and movement and benefit from learning through games and drama(Oxford, 2201a, 2001b,2003; Cohen, 2003; Reid, 1995).

Learning styles are different from learning strategies which are specific behaviours or techniques learners use such as grouping words, holding mental conversations with themselves, getting someone to read aloud to them, watch- 
ing TV, etc. The strategies chosen are often linked to the individual's learning style. Following a text while it is read aloud is helpful for visually oriented learners, while watching TV can suit auditory learners(Reid, 1995; Cohen, 2003; Ehermen\& Leaver, 2003; Oxford, 2001a, 2001b, 2002; Oxford \& Anderson, 2003,Ehermen\& Oxford, 1990).

The importance of learners' perceptual learning styles and strategies is also addressed in the realm of English for Specific Purposes (ESP). Widdowson (1983) emphasizes the need to integrate learning styles and strategies that the learners have developed through their specialism into the methodology of ESP. According to him, ESP courses could lead to desirable outcomes if the processes through which the learners have developed their learning styles and strategies in their technical field are integrated into the teaching methodology.

In so doing, first, there needs to be an investigation of the learners' preferred learning styles, developed in their specialism fields, and identifying possible relationships their learning styles could bear with their learning strategies in different language skills such as reading comprehension. As the next step, particular tasks could be devised to meet those learning styles and strategies. In university level, as learners come from different educational backgrounds and also pursue their studies in different fields, it is expected that their learning styles and strategies differ; requiring different class methodologies, techniques and tasks in their ESP courses to best suit their learning experiences.

\section{Objectives of the Study}

As part of a $\mathrm{PhD}$ dissertation, the present study aims at identifying Art and Engineering students' preferred perceptual learning styles, developed through their specialism fields in an Iranian context. It also seeks to identify the preferred reading strategies Art and Engineering students apply for dealing with their technical texts in ESP courses. Finally, this study aims at investigating possible relationships between Art and Engineering students' preferred learning styles and their reading strategies for tackling technical reading texts in their ESP courses. Therefore, the following research questions are considered:

1- Is there any significant correlation between Art students' learning styles and their reading strategies in ESP materials in academic settings?

2- Is there any significant correlation between Engineering students' learning styles and their reading strategies in ESP materials in academic settings?

\section{REVIEW OF THE RELATED LITERATURE}

Learning styles are defined by Reid (1995, p. vii) as "an individual's natural, habitual, and preferred way(s) of absorbing, processing, and retaining new information and skills." For her, learning styles are best divided into three main categories: cognitive, sensory, and personality. In the past decades, the research in this field has focused mostly on cognitive learning styles (Cohen, 2003; Ehrman\& Leaver,2003; Ehrman\& Oxford, 1990; Rossi-Le, 1995), which are defined as the learners' most preferred and habitual approach to organizing and representing information (Riding \&Rayner, 1998).

In another classification, Oxford (2003) represents cognitive learning styles as auditory, visual, kinesthetic (movement-oriented) and tactile (touch-oriented). She believes that cognitive preferences refer to the physical, perceptual learning channels with which the student is the most comfortable. For example, visual students prefer to gain information from visual stimulation such as reading extensively. So for a learner with this orientation, other information channels such as lectures or conversations can be confusing. On the other hand, auditory learners are most comfortable with the flow of information in the form of auditory channels such as oral directions, speeches or lectures. Kinesthetic and tactile learners enjoy movements and touching experiences. They also enjoy working with tangible objects, flashcards, etc. These learners get easily bored if seated for long hours before desks or at tables and need to have frequent breaks and moves around the studying place (Kinsella, 1995; Oxford, 2003; Ehermen\& Leaver, 2003).

Reid (1987) showed that ESL students have significant variations with respect to their sensory (perceptual) learning styles and cultural background is a prominent factor in this respect. She found that students from different cultural backgrounds favored certain learning styles. For instance, students from Asian cultures are often highly visually-oriented and Hispanic learners are mostly auditory. Kinsella (1995) also reported that Asian students look for structural learning, with a teacher as an authority figure and are less comfortable with autonomous learning and situations where there are several acceptable answers, whereas Hispanics tend to develop a more globally-oriented learning style which favors flexibility and negotiations and still Anglo-Americans are more analytical who want planned, methodical approaches.

Research studies have shown that learning can be enhanced by teaching in ways that encourage students to activate their own learning styles (Dunn \& Griggs, 1990). This suggests that teachers need both to ascertain their learners' styles and to recognize similarities and differences with their own. Questionnaires (examples in Reid, ed., 1995), interviews and discussions can be used to raise awareness and an understanding of these issues.

Ajideh and Gholami (2014) studied learning styles as the predicators of test performance among 152 BA English students. They concluded that out of the four learning styles of theorist, activist, reflective, and pragmatist as possible predictors, only reflective and pragmatist styles accounted for a statistically significant portion of the variance in the final test performance.

Another significant issue that is also suggested is the need to activate and build on the learning styles and strategies which have been developed through the specialist field, that is through the academic and professional culture. Dudley-Evans and St John (1998) recommend that if observation and deduction are central to the learning style of scientists then in helping them to learn the language whichthey need in their specialist field we can attempt to activate those same 
processes. For example, deducing grammatical patterns can be more effective than being told about them. Extracting information into tables, flowcharts and other diagrammatic formats is more natural for EST learners than for their teachers(Riding \&Rayner, 1998). The need to integrate cognitive learning process in ESP methodology is also stressed by Widdowson (1983, pp. 108-9) when he wrote " ESP is (or ought logically to be) integrally linked with areas of activity (academic, vocational, professional) which represent the learners' aspirations".

There has been some research on identifying the perceptual learning styles preferences and their possible relationship with learning strategies among Iranian students (Naserieh\&Anani, 2013; Sahragard, et al., 2014, Moradkhan\&Mirtaheri, 2011; Banisaeid\&Huang, 2015; Barzghar\&Tajjali, 2013, Jowkar, 2012; Chavosh\&Davoudi, 2016) but the notion of the relationship between learners' perceptual learning styles and reading strategies in ESP has not been much scrutinized in academic settings in Iranian context.

\section{METHODOLOGY}

\section{Participants}

The participants involved in this study were totally 313 male and female, first and second-year undergraduate students at Tabriz Islamic Art University. They included Art $(n=165)$ and Science $(n=148)$ students from three different faculties. In the questionnaires distributed, the participants were asked to define their background field of study at school according to the four categories of Mathematics, Biology, Humanities and Arts. The participants at Art group all came from Art schooling background and those in Science group came from Mathematics schooling background.Some165 participants (88 female and 77 male) were studying Art subjects such as Carpet Design and Islamic Arts and 148 participants (72 female and 76 male) were studying Science subjects such as Architecture Engineering and Urbanism Engineering.

\section{Instruments}

To collect the quantitative data for the study, two self-report questionnaires were employed. The PLSPQ was used to identify the major, minor and negligible learning style preferences of the students and the SORS Inventory was used to identify the pattern of reading strategies (cognitive, metacognitive and support strategies) employed by the students in ESP reading materials.

\section{Perceptual learning style preferences questionnaire (PLSPQ)}

Developed by Reid (1984), the PLSPQ measures the students' preferred learning styles. This is one of the first learning style measures widely known in the ESL/EFL field. It consists of 30 randomly ordered statements for six learning style preferences (five statements on each learning style):

- Visual (e.g., "I learn better by reading than by listening to someone")
- $\quad$ Auditory (e.g., "I learn better in class when the teacher gives a lecture")

- $\quad$ Kinesthetic (e.g., "I prefer to learn by doing something in class")

- $\quad$ Tactile (e.g., "I learn more when I make something for a class project")

- Individual (e.g., "When I study alone, I remember things better")

- Group (e.g. "I learn more when I study with a group")

The questionnaire is based on a five-point Likert scale, ranging from 1 (strongly disagree) to 5 (strongly agree). As reported by Reid (1987, p. 92), the PLSPQ wasnormalized on non-native speakers, and the "validation of the questionnaire was doneby the split-half method. Correlation analysis of an original set of 60 statements (tenper learning style) determined which five statements should remain within eachsubset". Later, in order to "[wash] the dirty laundry of [her] learning stylesresearch," Reid (1990, p. 336) offered a more detailed account of the proceduresadopted for constructing and validating the questionnaire. Reid (1995) also classifiedstyles as eithermajor, minor, or negligible (or negative). Major is a preferred learningstyle, minor is one in which learners can still function, and negligible means they mayhave difficulty learning in that way. In order to obtain the score for each subset of learning styles, she prescribed adding the scores for each learning style and multiplying the obtained score by 2 . She also set cut off points for each of these categoriesin the scoring sheet of the questionnaire: major( $\mathrm{M}=38-50)$; minor ( $\mathrm{M}=25$ to 37$)$; and negligible( $\mathrm{M}=24$ or less).

\section{Survey of reading strategies (SORS)}

SORS was developed by Sheorey and Mokhtari (2001) and is intended specifically to discover the reading strategies purportedly used by post-secondary students who are native or non-native speakers of English. This instrument is based on the Metacognitive-Awareness-of-Reading-Strategies Inventory (MARSI), which was originally developed by Mokhtari (1998-2000) as a tool for measuring native speaking students' awareness and use of reading strategies while reading academic or school-related materials. MARSI was validated using a large native speaker population $(n=825)$, representing students with reading abilities ranging from middle school to college. The internal consistency reliability coefficients (as determined by Cronbach's alpha) for its three subscales, which were based on the results of factor analysis, were as follows: Metacognitive (0.92), Cognitive (0.79), and Support strategies (0.87). The reliability of the overall scale was 0.93 , indicating a reasonably dependable measure of metacognitive awareness of reading strategies. A brief description of the categoriesSORS measures and the number of items within each category are given below:

1. Metacognitive strategies are those intentional, carefully planned techniques by which learners monitor or manage their reading. Such strategies include having a purpose in mind, previewing the text as to its length and organization, or using typographical aids and tables and figures (10 items). 
2. Cognitive Strategies are the actions and procedures readers use while working directly with the text. These are localized, focused techniques used with problems develop in understanding textual information. Examples of cognitive strategies include adjusting one's speed of reading when the material becomes difficult or easy, guessing the meaning of unknown words, and re-reading the text for improved comprehension (12 items).

3. Support strategies are basically support mechanisms intended to aid the reader in comprehending the text such as using a dictionary, taking notes or underlining or highlighting the text to better comprehend it (6 items).

\section{Procedure}

The preparation of the questionnaires introduced above began by translating the original English versions into Persian ones, since they were supposed to be given to students with Persian language backgrounds. The translated versions were given to three competent English Language teachers to read and comment on any mistranslations or ambiguities in the process of translation. After their comments were applied in the translated versions of PLSPQ and SORS, they were given to a group of students at Tabriz Islamic Art University $(n=25)$ to pilot-test the questionnaires and find out if the items were comprehensible enough or if they contained any ambiguities for the purposes they intended. The results of this pilot-test was some minor modifications in the wording of three items which was believed to increase the clarity of the items and eliminate the need for further explanation by teacher during administering them with the target population.

The questionnaires, then, were given to the intended population to read and carefully choose the box which best describes their learning style or reading strategies. Before the students answered the items of the questionnaires, a brief explanation of the questionnaires and the intentions behind them was given to the students. The data with the questionnaires were gathered during the studying terms of 2016.

The data from the questionnaires were transferred to SPSS software version 22 and correlational analyses (Pearson Product moment coefficient r) were applied on the variables of the study.

\section{RESULTS}

\section{Learning Styles Preferences among Art and Science Students}

The analysis of the mean scores on the PLSPQ questionnaires based on the cut off points introduced by Joy Reid (1995) revealed that Art students favored Tactile, Kinesthetic, Auditory and Group learning styles as their major learning style. Moreover, Visual and Individual learning styles were found to be their minor learning styles. No learning styles were found as negligible ones ( $\mathrm{M}=$ less than 24). With respect to Science students' responses, the analysis showed that the single major learning style for these students was Kinesthetic and all other styles scored as minor learning styles. (See Tables 1-2)

In other words, Art and Science students at Tabriz Islamic Art University learn best when they have the opportunity to do "hand-on" experiences with materials. That is, working on experiments in a laboratory, handling and building models, and touching and working with materials provide them with the most successful learning situation. Writing notes or instructions can help them remember information, and physical involvement in class related activities may help them understand new information. These students also learn best by experience, by being involved physically in classroom experiences. They also remember information well when they actively participate in activities, field trips, and role-playing in the classroom. A combination of stimuli, for example, an audio tape combined with an activity, will help them understand new materials. Art and Science students, moreover, learn from hearing words spoken and from oral explanations. They may remember information by reading aloud or moving their lips as they read, especially when they are learning new materials. They benefit from hearing audio tapes, lectures, and class discussion.

With respect to their social characteristics, the analyses also suggest that, these students favor group learning; that is, they learn more easily when they study at least with one other student, and they will be more successful completing work well when they work with others. These students value group interaction and class work with other students and they remember information better when they work with two or three classmates. The stimulation they receive from group work helps them learn and understand new information.

Table 1. Descriptive statistics of learning style preferences among art students

\begin{tabular}{|c|c|c|c|c|c|c|c|}
\hline & \multirow{2}{*}{$\frac{\mathrm{N}}{\text { Statistic }}$} & \multirow{2}{*}{$\begin{array}{c}\text { Minimum } \\
\text { Statistic }\end{array}$} & \multirow{2}{*}{$\begin{array}{c}\text { Maximum } \\
\text { Statistic }\end{array}$} & \multicolumn{2}{|r|}{ Mean } & \multirow{2}{*}{$\begin{array}{c}\text { Standard deviation } \\
\text { Statistic }\end{array}$} & \multirow{2}{*}{$\begin{array}{l}\text { Variance } \\
\text { Statistic }\end{array}$} \\
\hline & & & & Statistic & Standard error & & \\
\hline Kin. & 165 & 28.00 & 48.00 & 41.8788 & 0.48987 & 6.29245 & 39.595 \\
\hline Aud. & 165 & 30.00 & 48.00 & 40.0606 & 0.51652 & 6.63481 & 44.021 \\
\hline Vis. & 165 & 22.00 & 46.00 & 34.3879 & 0.52121 & 6.69509 & 44.824 \\
\hline Tac. & 165 & 36.00 & 50.00 & 43.1273 & 0.32318 & 4.15135 & 17.234 \\
\hline Gro. & 165 & 30.00 & 46.00 & 38.0121 & 0.35006 & 4.49659 & 20.219 \\
\hline Ind. & 165 & 20.00 & 50.00 & 34.7273 & 0.56743 & 7.28878 & 53.126 \\
\hline Valid N (likewise) & 165 & & & & & & \\
\hline
\end{tabular}




\section{Reading Strategies Applied by Art and Science Students in ESP Reading}

The participants' responses to SORS questionnaires which were intended to measure their awareness of the reading strategies they apply when reading ESP materials were analyzed and the results of the mean scores are shown in Tables 3-4.

As the tables show, the most frequent reading strategies Art and Science students apply in their ESP reading activities were Cognitive Strategies $(M=39.7455$ and $M=39.3041$, respectively).

\section{Correlation between Art Students' Learning Style Preferences and Reading Strategies}

In order to find any possible correlation between Art students' preferred learning style(s) and their self reported awareness of strategies applied in ESP reading, Pearson Moment Correlation test was conducted on the acquired data. The results of the analyses showed that, among all major learning styles of Art students in this study, i.e. Tactile, Kinesthetic, Auditory and Group learning styles, only their Auditory learning style significantly correlated with their cognitive reading strategy (see Table 5).

Table 5 shows the Pearson Moment Correlation value obtained between Art students' Auditory learning style and their Cognitive reading strategies they apply in their ESP readings. According to the results obtained by Pearson Moment test, the $P$ value is 0.028 which is smaller than 0.05 (p $<0.05$ ) and the correlation is revealed to be significant. This means that there is a meaningful relationship between Art students' Auditory learning style and their cognitive reading strategies. Therefore, we can answer the first research question of this study which sought to find any possible correlation between Art students' preferred learning style(s) and their ESP reading strategy. There was found to be a significant correlation between Art students' major learning style, i.e. Auditory, and their ESP reading strategy, i.e. cognitive.

This suggests Art students with Auditory learning style can benefit from hearing words spoken and from oral explanations. They may remember information by reading aloud or moving their lips as they read, especially when they are learning new materials. According to Sheorey and Mokhtari's classification of reading strategies, Reading Aloud is considered as a cognitive strategy that is used when the reader finds

Table 2. Descriptive statistics of learning style preferences among science students

\begin{tabular}{|c|c|c|c|c|c|c|c|}
\hline & \multirow{2}{*}{$\frac{\mathrm{N}}{\text { Statistic }}$} & \multirow{2}{*}{$\begin{array}{c}\text { Minimum } \\
\text { Statistic }\end{array}$} & \multirow{2}{*}{$\begin{array}{c}\text { Maximum } \\
\text { Statistic }\end{array}$} & \multicolumn{2}{|r|}{ Mean } & \multirow{2}{*}{$\frac{\text { Standard deviation }}{\text { Statistic }}$} & \multirow{2}{*}{$\begin{array}{l}\text { Variance } \\
\text { Statistic }\end{array}$} \\
\hline & & & & Statistic & Standarderror & & \\
\hline Kin. & 148 & 20.00 & 50.00 & 38.4730 & 0.50384 & 6.12949 & 37.571 \\
\hline Aud. & 148 & 24.00 & 50.00 & 36.9730 & 0.40246 & 4.89613 & 23.972 \\
\hline Vis. & 148 & 24.00 & 50.00 & 36.0541 & 0.42185 & 5.13198 & 26.337 \\
\hline Tac. & 148 & 14.00 & 48.00 & 35.7568 & 0.60119 & 7.31378 & 53.491 \\
\hline Gro. & 148 & 10.00 & 50.00 & 33.2973 & 0.85840 & 10.44289 & 109.054 \\
\hline Ind. & 148 & 18.00 & 50.00 & 32.7027 & 0.75492 & 9.18403 & 84.346 \\
\hline Valid N (likewise) & 148 & & & & & & \\
\hline
\end{tabular}

Table 3. Descriptive statistics of the awareness of reading strategies applied by art students in ESP readings

\begin{tabular}{|c|c|c|c|c|c|c|c|}
\hline & \multirow{2}{*}{$\begin{array}{c}\mathbf{N} \\
\text { Statistic } \\
\end{array}$} & \multirow{2}{*}{$\begin{array}{c}\text { Minimum } \\
\text { Statistic }\end{array}$} & \multirow{2}{*}{$\begin{array}{c}\text { Maximum } \\
\text { Statistic } \\
\end{array}$} & \multicolumn{2}{|r|}{ Mean } & \multirow{2}{*}{$\begin{array}{c}\text { Standard deviation } \\
\text { Statistic } \\
\end{array}$} & \multirow{2}{*}{$\begin{array}{l}\text { Variance } \\
\text { Statistic } \\
\end{array}$} \\
\hline & & & & Statistic & Standard error & & \\
\hline MET. & 165 & 20.00 & 35.00 & 30.2000 & 0.29334 & 3.76797 & 14.198 \\
\hline COG. & 165 & 30.00 & 49.00 & 39.7455 & 0.33293 & 4.27650 & 18.288 \\
\hline SUP. & 165 & 13.00 & 34.00 & 22.6364 & 0.36878 & 4.73710 & 22.440 \\
\hline Valid N (likewise) & 165 & & & & & & \\
\hline
\end{tabular}

Table 4. Descriptive statistics of the awareness of reading strategies applied by science students in ESP readings

\begin{tabular}{|c|c|c|c|c|c|c|c|}
\hline & \multirow{2}{*}{$\begin{array}{c}\text { N } \\
\text { Statistic }\end{array}$} & \multirow{2}{*}{$\begin{array}{c}\text { Minimum } \\
\text { Statistic }\end{array}$} & \multirow{2}{*}{$\begin{array}{c}\text { Maximum } \\
\text { Statistic }\end{array}$} & \multicolumn{2}{|r|}{ Mean } & \multirow{2}{*}{$\begin{array}{c}\text { Standard deviation } \\
\text { Statistic }\end{array}$} & \multirow{2}{*}{$\begin{array}{l}\text { Variance } \\
\text { Statistic }\end{array}$} \\
\hline & & & & Statistic & Standard error & & \\
\hline MET. & 148 & 16.00 & 42.00 & 31.0676 & 0.48051 & 5.84571 & 34.172 \\
\hline COG. & 148 & 25.00 & 48.00 & 39.3041 & 0.41090 & 4.99886 & 24.989 \\
\hline SUP. & 148 & 15.00 & 35.00 & 25.6081 & 0.43566 & 5.30003 & 28.090 \\
\hline $\begin{array}{l}\text { Valid } \\
\text { N (likewise) }\end{array}$ & 148 & & & & & & \\
\hline
\end{tabular}


the reading material difficult to understand. In fact, reading aloud stimulates the imaginations and emotions; models good reading behavior; exposes the readers to a range of literature; enriches their vocabularies and understanding of sophisticated language patterns; makes difficult text understandable; models the fact that different genres are read differently; supports independent reading; and can encourage a lifelong enjoyment of reading. In other words, when the students embark on reading their ESP reading aloud to themselves, they are activating their Auditory Learning style and are, in fact, utilizing this major learning style.

\section{Correlation between Science Students' Learning Style Preferences and Reading Strategies}

In order to find any possible correlation between Science students' preferred learning style(s) and their self reported awareness of strategies applied in ESP reading, Pearson Moment Correlation test was conducted on the acquired data and the results are reported in Table 6 .

According to the above Table, the $\mathrm{P}$ value for Pearson Moment Correlation Test is 0.000 which is smaller than 0.05 $(p<0.05)$. In other words, there is a significant correlation between Science students' Kinesthetic learning style, as their single major learning style, and their cognitive reading strategies they apply in their ESP reading. Therefore, we can answer the second research question of this study which sought to find any possible correlation between Science students' preferred learning style and their ESP reading strategy. There was found to be a significant correlation between Science students' major learning style, i.e. Kinesthetic, and their ESP reading strategy, i.e. cognitive.

\section{DISCUSSION}

As it was stated before, learning style(s), a major individual factor affecting the success or failure of the learners (Kinsella, 1995; Cohen, 2003; Oxford, 2003), is a concept that has attained considerable attention by different researchers in EFL/ESL classes in Iran. For instance, in a study to explore the preferred learning style preferences of Iranian EFL students, Banisaeid and Huang (2015) found that Iranian EFL students favor all perceptual learning styles of Visual, Auditory, Kinesthetic and Tactile, but they favor to learn individually rather than in groups. Considering the Iranian EFL language learning strategies, they found that cognitive and metacognitive strategies were mostly used by them, while affective strategies were the least-used favored strategies. They added that, learners also used metacognitive self-regulation and time and study environment, more than other self-regulated learning strategies. This study also revealed that more self-regulated learners were auditory and visual learners, while less self-regulated learners were more tactile and preferred group and individual learning but learners with more language learning strategy uses favoured an auditory style.

In a similar study, Moradkhan and Mirtaheri (2011), investigated Iranian EFL learners' preferred learning styles. They collected data using Reid's (1978) Perceptual
Table 5. Pearson moment correlation test between auditory learning style and cognitive reading strategy among art students

\begin{tabular}{|c|c|c|}
\hline \multicolumn{3}{|l|}{ Correlations art } \\
\hline & Aud & COG \\
\hline \multicolumn{3}{|l|}{ Aud } \\
\hline Pearson Correlation & 1 & $-0.171^{*}$ \\
\hline Sig. (2-tailed) & & 0.028 \\
\hline $\mathrm{N}$ & 165 & 165 \\
\hline \multicolumn{3}{|l|}{$\mathrm{COG}$} \\
\hline Pearson Correlation & $-0.171 *$ & 1 \\
\hline Sig. (2-tailed) & 0.028 & \\
\hline $\mathrm{N}$ & 165 & 165 \\
\hline
\end{tabular}

Table 6. Pearson moment correlation test between kinesthetic learning style and cognitive reading strategy among science students

\begin{tabular}{|c|c|c|}
\hline \multicolumn{3}{|l|}{ Correlations science } \\
\hline & Kin & COG \\
\hline \multicolumn{3}{|l|}{ Kin } \\
\hline Pearson Correlation & 1 & $0.426 * *$ \\
\hline Sig. (2-tailed) & & 0.000 \\
\hline $\mathrm{N}$ & 148 & 148 \\
\hline \multicolumn{3}{|l|}{ COG } \\
\hline Pearson Correlation & $0.426^{* *}$ & 1 \\
\hline Sig. (2-tailed) & 0.000 & \\
\hline $\mathrm{N}$ & 148 & 148 \\
\hline
\end{tabular}

Learning Style Preferences Questionnaire (PLSPQ) from 112 students and found that these learners' major learning style was Kinesthetic. They also showed a significant relationship between perceptual, learning style and the age of the learners.

Along with identifying the preferred perceptual learning styles, researchers also attempted to find possible relationships between learners' learning styles and other variables. For example, in order to find possible relationships between perceptual learning styles and reading comprehension performance among Iranian EFL learners, Chavosh and Davoudi (2016) carried out a study on 60 Iranian EFL learners. The results of their study indicated that only kinesthetic and tactile learning styles had a significant relationship with L2 reading comprehension performance. They also showed that the tactile learning style was the best predicator of L2 reading comprehension performance. Along with the same line, Barzegar and Tajjali (2013) investigated the relationship between learning styles of advanced Iranian EFL learners and their class achievement. They used Pearson Moment Correlation test to analyzed the acquired data from sixty male and female advanced English learners and found that, first, the kinesthetic and group learning styles were mostly favored 
by these learners and, second, these preferred learning styles positively correlated with their class achievements.

Another study which has significant correlation with the present study is the one conducted by Naserieh and Anani (2013), in which perceptual learning style preferences of graduate university learners in different disciplines were investigated. They reported that learners in technical fields favor tactile learning style more than other styles and reason that this may be related to the greater skills of such students in activities such as model building, collage making, and working in laboratories as an essential part of their career. On the other hand, students in social sciences and humanities where cooperation and mutual support does not seem as an essential part of their discipline were found to favor an individual-oriented learning style.

The findings in the above mentioned studied are somehow in line with the findings of this study. With respect to Art students' major learning style preferences in this study, it can be discussed that these students favor working with hands-on training programs. They tend to touch things to learn about their characteristics and features. They also learn best when new information is presented in auditory ways like when they listen to a lecture or some instructions read to them. Working in groups is also preferred by Art students. This is the reason why many of their courses in their curriculum encourage them for group work such a when they work on a project for a course like Color Properties.

When it comes to the benefits that knowledge of Art students learning styles preferences can have in their ESP reading courses, it can be claimed that, for a more successful learning experiences in their ESP courses, Art learners need to be exposed to many practical tasks, auditory exercises and pair/group works.

Most of the time, under-graduate University students in Iran in general and under-graduate Art students at Tabriz Islamic Art University in particular receive lessons in their ESP courses in traditional English-to-Persian translation method. The ultimate aim is the understanding of the ESP texts in Persian. That may be one reason why they do not obtain the desired results they look for at higher education examinations such as TOEFL or IELTS. In many cases, they feel the need to take up supplementary studies in Technical English when they want to pursue their studies in post-graduate levels.

Considering their learning style preferences, Art students seem to benefit from a task-based approach to language teaching. Task-based language Teaching (TBLT), also known as task-based instruction (TBI), was popularized by Prahbu (1987) and focuses on the use of authentic language and on asking students to do meaningful tasks using the target language. Such tasks can include visiting a doctor, conducting an interview, or calling customer service for help.

As the analysis of the data with Science students showed in this study, the major learning style preference among these students was Kinesthetic learning style and other learning styles such as Visual, Auditory, Tactile, Group and Individual learning styles were discovered to be minor learning styles among Engineering students at Tabriz Islamic Art
University. As with their major learning preference, these students favor learning by experience, by being involved physically in classroom experiences. They remember information well when they actively participate in activities, field trips, and role-playing in the classroom. This can be the reason why there are many instances of field-trip programs in their curriculum which give them opportunities to visit architectural elements on the site and experience their learned materials with real objects. These students travel to different cities and have on-site visits of buildings and architectural structures and study their properties and features.

When it comes to the benefits that knowledge of Science students' learning styles preferences can have in their ESP reading courses, it can be claimed that, for a more successful learning experiences in their ESP courses, Science learners need to be exposed to many practical tasks, experiential learning activities and reflections on doing exercises.

With regard to Science students' major learning preference as Kinesthetic learning style, it seems that these students can be benefited from experiential language learning model. Experiential learning is the process of learning through experience, and is more specifically defined as "learning through reflection on doing". Hands-on learning is a form of experiential learning but does not necessarily involve students reflecting on their product. Experiential learning is distinct from rote or didactic learning, in which the learner plays a comparatively passive role. It is related to but not synonymous with other forms of active learning such as action learning, adventure learning, free-choice learning, cooperative learning, service-learning, and situated learning. (Felicia, 2011)

In his book entitled Constructivist Blended Learning Approach to Teaching English for Specific Purposes, Oleg Tarnopolsky (2012), gives an in depth account of his model of experiential teaching for ESP courses at tertiary school. $\mathrm{He}$ introduces experiential learning activities such as role playing professional situations in the target language in ESP, simulating professional activities by means of the target language in ESP, project work in ESP teaching and learning, and experiential learning activities and teaching different communicative and language skills in ESP. He also introduces ways for preparing ESP teachers for teaching in content-based experiential ESP courses for tertiary students

There has been ample research on experiential learning among researchers. For instance, Mollaei and Rahnama (2012) offer a historical background of how experiential education has emerged, and how it has been adapted to the field of language education. They focused on identifying the concept of experiential learning, an experiential learning cycle, its principles and criteria, weaknesses and strengths.

Wei Li (2013) worked on the development of transcripts in experiential and web-mediated ESP learning with police trainees. In his study, the students experienced real scene of their future work and retrieved transcripts which had been downloaded from English speaking websites as sources of experiential and web-based English for Policing. The results showed that most of the students enjoyed and thought highly of the experiential ESP learning. Students commented that 
the course was practical, useful and the scenario was vivid and lively, closely related to police work, rich in content and very enjoyable. He also reported some disadvantages observed in his study and introduced possible solutions. For instance, the participants in his study complained about too many new words in the conversations and negative characters' speaking too fast for them to understand. He suggested a solution to some of the difficult audio and video transcripts by adding more textual explanations or more background introduction prior to the learning.

With regard to what has been presented about experiential learning and the research conducted in this area, it can be suggested that Science students at Tabriz Islamic Art university (Architectural and Urbanism Engineering students) can experience an enjoyable ESP learning if they are designated to professional role-plays, project works, on-site professional visits of architectural monuments and discussing their features and characteristics, listening to or watching professional lectures in their field and commenting on what they have listened to/watched, etc. These activities, it can be claimed that, needs advanced language abilities in the part of the students such as a good command of listening comprehension and speaking skills and to expect the students in our context to live up to high expectations is an idealism. But it should be born in mind that ESP courses are always presented at universities after they pass courses for general English, which can give a suitable chance, though not sufficient, for the students to develop the necessary skills needed to be engaged in experiential learning activities in their later ESP courses.

\section{CONCLUSION}

The aim of the present study was to identify Art and Science undergraduate students' perceptual learning styles and their preferred reading strategies while reading their technical texts. It also aimed at shedding light on the possible relationship between these students' perceptual learning styles preferences and their ESP reading strategies. The analysis of the PLSPQ self report questionnaire which intended to identify these students' perceptual learning styles preferences showed that Art students favored Tactile, Kinesthetic, Auditory and Group learning styles as their major learning styles. Other learning styles in Reid's (1984) classification as Visual and Individual styles were found to be minor styles among these students. The results also indicated that, among Science students studying engineering subjects, the only major learning style was Kinesthetic and all other perceptual learning styles were shown to be minor. In other words, it can be claimed that Art students learn best when they involve actively in learning experiences, have opportunities for hands-on training, are exposed to auditory information and work in groups. Science students, on the other hand, can best capitalize on their learning potentials when they have opportunities to be involved physically in the classroom experiences. They remember information well when they actively participate in activities, field trips, and role-play in the classroom.

The analysis of the other self-report questionnaire, SORS, which sought to elicit the students' favored reading comprehension strategies in ESP texts indicated that both Science and Art students used cognitive strategies to tackle their ESP texts. The Analysis of the correlation between Science and Art students' preferred perceptual learning styles and their reading strategies showed that only Auditory learning style of the Art students and the Kinesthetic learning style of the Science students statistically correlated with their ESP reading strategy, i.e. cognitive strategies.

Considering the correlational analyses, it can be suggested that in order to facilitate Art students' ESP reading comprehension and help them improve their achievements in ESP reading, they need to be exposed to ample auditory learning experiences such as listening to lectures in their specialty field. With respect to the statistically meaningful relationship between Science students' major learning style and their cognitive reading strategies, it can also be suggested that these students be provided with many instances of active participation in classroom activities, field trips and role-play.

\section{ACKNOWLEDGEMENTS}

We would like to express our sincere thanks to the respected anonymous reviewers for their useful suggestions and comments on the earlier versions of this paper.

\section{REFERENCES}

Ajideh, P., Gholami, V. (2014).Learning styles as predicators of students' test performance.English Language Teaching,(1)3, 1-17.

Banisaeid, M., \& Huang, J. (2015). Exploring Iranian EFL learners' perceptual learning styles preferences, language learning strategy uses and self-regulated learning strategies. International Journal on Studies in English Language and Literature.3(3), 30-40.

Barzegar, F., \&Tajjali, Gh. (2013).Relationship between learning styles of advanced Iranian EFL learners and their achievement. Journal of Studies in Learning and Teaching English.1(4), 1-21.

Chavosh, M., \&Davoudi, M. (2016).The relationship between perceptual learning styles and reading comprehension performance of Iranian EFL learners.International Journal of English Linguistics. 6(3), 61-69.

Cohen, A. D. (2003). The learner's side of foreign language learning: where do styles, strategies, and tasks meet? IRAL: International Review of Applied Linguistics in Language Teaching, 41(4), 279-291.

Dudley-Evans, T. \& Jo st John, M. (1998).Developments in English for specific purposes.Cambridge University Pess.

Dunn, R., \& Griggs, S. (2003). Synthesis of the Dunn and Dunn learning styles model research: Who, what, when, where and so what-the Dunn and Dunn learning styles model and its theoretical cornerstone. St. Johns University, New York.

Ehrman, M., \& Leaver, B. L. (2003).Cognitive styles in the service of language learning.System, 31(3), 393-415. 
Ehrman, M. \& Oxford, R.(1990). Adult language learning styles and strategies in an intensive training setting." The Modern Language Journal 74(3), 311-327.

Ehrman, M. E., \& Oxford, R. L. (1991). Affective survey. Arlington, VA: Foreign Service Institute.

Ehrman, M. E., \& Oxford, R. L. (1995). Cognition plus: Correlates of language learning success. Modern Language Journal, 79(1), 67-89.

Jowkar, M. (2012). The relationship between perceptual learning style preferences and listening comprehension strategies of Iranian intermediate EFL learners.Academic Research International.2(2), 739-745.

Kinsella, K. (1995). Understanding and empowering diverse learners in the ESL classroom. In J. Reid (Ed.), Learning styles in the ESL/EFL classroom (pp. 170-194). Boston, MA: Heinle\&Heinle.

Li, W. (2013). Development and Application of Transcripts in Experiential and Web-mediated ESP Learning.International Journal of Engineering Research and Development.(6)5, 30-34.

Mollaei, F., Rahnama, H.R. (2012).Experiential education contributing to language learning.International Journal of Humanities and Social Sciences. (2) 21, 268-279

Moradkhani, D., \&Mirtaheri, S. (2011). The relationship between Iranian EFL learners' perceptual; learning styles and their teachers' teaching styles.Journal of English Studies. 1(4) 41-52.

Naserieh, F., \&Anani, M. R. (2013). Perceptual learning style preferences among Iranian graduate students. System 41(1), 122-133.

Oxford, R. L. (2001a). Language learning strategies. In R. Carter \& D. Nunan (Eds.), The Cambridge guide to teaching English to speakers of other languages (pp. 166-172). Cambridge: Cambridge University Press.

Oxford, R. L. (2001b). Language learning styles and strategies. In M. Celce-Murcia (Ed.), Teaching English as a second or foreign language (pp. 359-366). Boston: Heinle\& Heinle.

Oxford, R. L. (2002). Language learning strategies in a nutshell: Update and ESL suggestions. In J. C. Richards \& W. A. Renandya (Eds.), Methodology in language teach- ing: An anthology of current practice (pp. 124-132). Cambridge: Cambridge University Press.

Oxford, R. L., \& Anderson, N. J. (1995). A crosscultural view of learning styles.Language Teaching, 28, 201-215.

Prabhu, N. S. (1987). Second language pedagogy.Oxford University Press.

Reid, J. (1987). The learning style preferences of ESL students.TESOL Quarterly, 21(1), 87-111.

Reid, J. (1990). The dirty laundry of ESL survey research. TESOL Quarterly, 24(2), 323-338.

Reid, J. (1995). Learning styles in the ESL/EFL classroom. Boston: Heinle\&Heinl Publications

Reid, J. (1996). A learning styles unit for the intermediate ESL/EFL writing classroom.TESOL Journal, 6(1), 42-47.

Reid, J. M. (1984). Perceptual learning style preference questionnaire. Laramie: University of Wyoming, Department of English.

Riding, R. J., \&Rayner, S. (1998). Cognitive styles and learning strategies: Understanding style differences in learning and behaviour. London: D. Fulton Publishers.

Rossi-Le, L. (1995).Learning styles and strategies in adult immigrant ESL students. In J. M. Reid (Ed.), Learning styles in the ESL/EFL classroom (pp. 118-125). New York: Heinle.

Rossi-Le, L. (1989).Perceptual learning style preferences and their relationship to language learning strategies in adult students of English as a second language. Unpublished doctoral dissertation, Drake University, Des Moines.

Sahraghard, R., Khajavi, Y., Abbasian, R. (2014). Field of study, learning styles, and language learning strategies of university students: Are there any relations? Innovation in Language Learning and Teaching, 10(3), 255-271.

Sheorey, R., \&Mokhtari, K. (2001). Differences in the metacognitive awareness of reading strategies among native and non-native readers. System, 29(4), 431-449.

Tarnopolsky, O. (2012). Constructivist blended learning approach to teaching English for specific purposes. Versita Ltd. London.

Widdowson, H. (1983). Learning purpose and language use. Oxford: Oxford University Press. 